УДК: 519.863:623.618 (477)

JEL Classification: C02

A. I. CEITHCB,

доктор технічних наук, професор, дійсний член Міжнародної академії комп'ютерних наук та систем, заслужений діяч науки і техніки Украйни В. В. КОЗЛОВ, кандидат технічних наук, дочент кафедри інформачійних технологій, Начіональна академія статистики, обліку та аудиту

\title{
Пошук глобального екстремуму в задачі розподілу пов'язаних ресурсів
}

У роботі запропоновано розиирення алгоритму сформульованої узагальненої математичної задачі розподілу взаємопов'язаних ресурсів для поиуку глобального екстремуму.

Ключові слова: алгоритм, пов'язані ресурси, розподіл ресурсів, глобальний екстремум.

Постановка проблеми. Методи розв'язання задач розподілу ресурсів посідають важливе місце серед математичних методів розв'язання спеціальних задач при прийнятті рішень щодо підготовки й проведення операції [1]. Ці методи використовувалися для розв'язання задач цілерозподілу, розподілу товарів за споживачами (замовниками) та інших. Однак масова комп'ютеризація, розвиток і впровадження новітніх інформаційних технологій привели до вражаючого ривка провідних країн світу в сферах освіти, наукових досліджень, економіки, соціального життя. Завдяки цим процесам відбувається бурхливий розвиток різних секторів економіки. 3'являються нові види товарів, основані на застосуванні інформаційних технологій, розвиваються автоматизовані системи управління економічними процесами. 3'явився новий вид ресурсу - інформаційний, характерною рисою якого $\epsilon$ внутрішчяя взаємопов'язаність. Задачі розподілу набули нового вигляду, що обумовлює актуальність пошуку нових алгоритмів розв'язання задач розподілу взаємопов'язаних ресурсів у напрямі пошуку локального і глобального екстремуму.

Аналіз останніх досліджень і публікацій. Як видно з огляду відомих прикладних задач розподілу ресурсів [8], практично всі завдання зводяться до завдань математичного програмування і оперують з незв'язаними ресурсами.

Систематизація прикладних задач розподілу ресурсів і методів їх розв'язання, a також аналіз сучасного стану задач розподілу ресурсів і методів їх рішення дозволяють зробити такі узагальнення:

$>$ серед можливих прототипів постановки задач розподілу зв'язаних ресурсів варто вибрати постановки завдань розподілу незв'язаних ресурсів (задачі математичного програмування);

$>$ серед методів - методи, основані на відсіканні, метод гілок і меж;

$>$ серед моделей - або моделі математичного програмування, або графові моделі [6, с. 102].

Виходячи $з$ особливостей задач розподілу ресурсів у автоматизованих інформаційних системах (AIC) для їх розв'язання підходять певні методи і моделі. Разом із тим потребують розвитку алгоритми для розв'язання нового класу задач розподілу зв'язаних ресурсів у напрямі пошуку локального і глобального екстремуму i, на їх основі, отримання методики оптимізації розподілу зв'язаних ресурсів з метою підвищення живучості AIC і оперативності доступу до даних за рахунок квазіоптимальної конфігурації розподіленої бази даних (БД) [7, с. 122].

А. І. Сбітнев, В. В. Козлов, 2017 


\section{МАТЕМАТИЧНІ МЕТОДИӴМОДЕЛІ ТА ІНФОРМАЦІЙНІ ТЕХНОЛОГЇ̈ В ЕКОНОМЦІ}

Мета дослідження - запропонувати розширення алгоритму, сформульованої узагальненої математичної задачі розподілу взасмопов'язаних ресурсів, для пошуку глобального екстремуму.

Виклад основного матеріалу. У роботі [2] сформульовано узагальнену математичну задачу розподілу взасмопов'язаних ресурсів (надалі - задача РВР). Наведено алгоритм ії розв'язання й показано, що цей алгоритм, маюочи лінійну складність, призводить до знаходження локального екстремуму. Нагадасмо зміст задачі.

Задано множину ресурсів $x_{i} \in X$, де $i=1,2, \ldots, n$. На множині $X$ задано функцію $F$, яка відображає множину на числову вісь, тобто кожному ресурсу $x_{i}$ ставиться у відповідність число $F\left(x_{i}\right)=f_{i}$ - "ціна" ресурсу. Зв'язок між ресурсами визначається відношенням $\Gamma \subseteq X \times X$, на якому вводиться функція $W$, що ставить у відповідність зв"язаній парі $\left(x_{i}, x_{j}\right)$ певне число $W\left(x_{i}, x_{j}\right)=w_{i j}$ - "вагу" зв'язку. Необхідно розподілити ресурси між $K$ об'ектани $O_{j}$ з прийлальники можливостями $p_{j}$, де $j=1, K$, так, иоб сунарна иіна ресурсів, ию потрапили до будь-якого об' 'ккma, не перевииувала його приймальної здатності, а сумарна вага зв'язків між ресурсани, ио потрапили до різних об' сктів, була мінімальною.

Розглянемо найпростіший частковий випадок, коли $K=2$, обмеження на $p_{j}$ відсутні, а всі $w_{i j}=1$, тобто розподіл вершин проводиться між двома множинами, а ваги однакові.

Нагадасмо алгоритм розв'язування спрощеної задачі [2]. Він базуеться на фіксації певного (вихідного) розподілу та його опису у вигляді кількості розсічених зв'язків, що названі нами розрізами. Вводяться поняття: "чужих" зв'язків, коли вершина однієї множини пов"язана із вершинами іншої множини; "своїх" зв'язків, коли вершина фіксованої множини пов'язана з вершинами тієї самої множини.

В основу алгоритму покладено ідею: якщо вершина має "чужих" зв'язків більше, ніж "своїх", їі потрібно перемістити в іншу множину. Якщо умова "иужих більще, нізк свойх" не виконусться, алгоритм зупиняється. Отримане значення, як доведено в роботі [2], є локальним екстремумом.

Для досягнення глобального екстремуму використасмо загальновідомий підхід:

1. Генеруємо деякий початковий розподіл.

2. Поліпшусмо його методом пошуку локального екстремуму, що викладений вище.

3. Після n-кратного виконання перших двох кроків отримані значення порівнюються, вибирасться найкраще, яке й приймається як значення глобального екстремуму.

Сутністю запропонованого в нашій роботі підходу $\epsilon$ використання як вихідної розбивки "природних" утворень на графовій моделі, яка використовується при фізичних інтерпретаціях розв'язуваних задач поданого класу [2; 4].

Введемо поняття околів і меж вершин для графів вигляду $G=(X, U)$ [3].

Buзначения 1. Першим околом $S_{i}^{1}$ вершини $x_{i}$ називаеться множина, що містить цю вершину й кінцеві вершини для дуг, ій інцидентних.

Для такої множини істинним $\epsilon$ висловлювання:

$$
\begin{gathered}
\forall x_{j} \in X\left\{x_{j} \in S_{i}{ }^{\prime} \leftrightarrow \exists\left\langle x_{i}, x_{j}>\left[\left(<x_{i}, x_{j}>\in U\right) \vee \dot{(}\left(x_{F}=x_{j}\right)\right]\right\},\right. \\
i, j \in I=\{1,2, \ldots, n\}, n=|X|\} .
\end{gathered}
$$

Тоді $n$-й окіл вершини $x_{i}$ за індукцією визначається через

$$
S_{i}^{n}=\quad \underset{x_{j} \in S_{i}^{n-1}}{u}
$$

Це означає, що $n$-й окіл вершини $x_{j}$ може бути отриманий шляхом додавання до $n$ 1-го околу множини сусідства, тобто кіневих вершин дуг, інцидентних вершинам із $S_{i}^{n-1}$. При цьому має місце:

$$
S_{i}^{\prime} \subseteq S_{i}^{2} \subseteq \ldots S_{i}^{n}
$$


Визначения 2. Першою межею $B_{i}{ }^{\prime}$ вершини $x_{i}$ називається множина вершин графу $G$, отримана за формулою:

$$
B_{i}^{1}=S_{i}^{1} \backslash\left\{x_{i}\right\} \text {. }
$$

Після введення базових понять подання графа $G=(X, U)$ потрібно зробити через перерахування перших околів його вершин:

$$
G=(X, U)=\left\{S_{i}^{\prime} \mid x_{i} \in X\right\} .
$$

Подання графів, похідних від первинного, легко отримати, опираючись на ї визначення.

Так, доповнення $\rceil_{G}$ можна отримати, використавши твердження:

$$
\left.\forall x_{i}\left[G=\left\{S_{i} \mid x_{i} \in X\right\} \rightarrow\right] G=\left\{\left(X \backslash S_{i}{ }_{i}\right) \cup i l x_{i} \in X\right\}\right] .
$$

Граф транзитивного замикання $\mathrm{G}^{\wedge}$ можна подати, використавши твердження [5]:

$$
\forall x_{i}\left[G=\left\{S^{\prime} \mid x_{i} \in X\right\} \rightarrow G^{\wedge}=\left\{S^{n}|n=| X \mid, x_{i} \in X\right\}\right] \text { i т.iн. }
$$

Подання арафів через базамокомпонентні кортежсі

Найзручнішим способом виразу завдання графів у вигляді околів і меж вершин для опису алгоритмів роботи над графами є трикомпонентні кортежі.

Кортеж вершини $x_{i}$ має вигляд:

$$
\alpha_{i}=\left\langle x_{i},\left|B_{i}\right|, B_{i}^{\prime}>\right.
$$

Для пояснення алгоритму знаходження глобального екстремуму шляхом введення околів скористуємося фізичною інтерпретацією моделі такої задачі: перервати з6 'язок між спожсивсчаи інформачї у інформаџійній мережс иляхом виведення з ладу мінікатьної кількості елементарних панок з6'язку за умови, ио початкові і кінцеві пункти зв 'язку відомі.

Необхідно знайти мінімальне число ребер, розсічення яких перериває всі илахи 3 вершини 1 у вершину 8.

Вважатимемо, шо вершиною, яка точно належить множині $A$, є вершина 1 , а вершиною, що точно належить множині В, є вершина 8 (рис. 1).

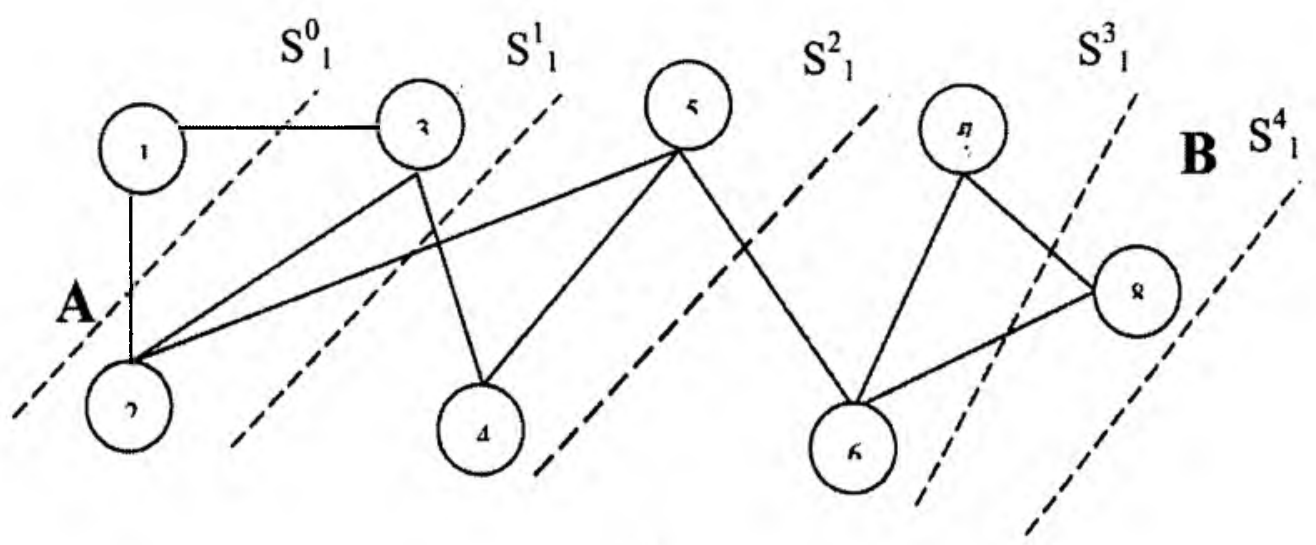

Рис. 1. Геометрична інтерпретація графа

Джерело: авторська розробка 
Побудуємо послідовні околи цієї вершини:

$$
\begin{aligned}
& \text { 1). } S_{1}^{0}=\{1\} \rightarrow A=\{1\} ; B=X \backslash A=\{2,3,4,5,6,7,8\} \text {; } \\
& \text { 2). } S_{1}^{1}=\{1\} \cup \mathrm{P}_{r 3} 1=\{1\} \cup\{2,3\} ; A=\{1,2,3\} ; B=\{4,5,6,7,8\} \text {; } \\
& \text { 3). } S_{1}^{2}=\bigcup_{i \in P_{r},} S_{i}^{1}=\{1\} \cup\{2,3\} \cup \mathrm{P}_{r 3} 2 \cup \mathrm{P}_{r 3} 3=\{1,2,3\} \cup\{1,3,5\} \cup\{1,2,4\}=\{1,2,3,4,5\} \text {; } \\
& A=\{1,2,3,4,5\} ; B=\{6,7,8\} \text {; } \\
& \text { 4). } S_{1}^{3}=S_{1}^{2} \cup \mathrm{P}_{r 3} 1 \cup \mathrm{P}_{r 3} 2 \cup \mathrm{P}_{r 3} 3 \cup \mathrm{P}_{r 3} 4 \cup \mathrm{P}_{r 3} 5= \\
& =\{1,2,3,4,5\} \cup\{2,3\} \cup\{1,3,5\} \cup\{1,2,4\} \cup\{3,5\} \cup\{2,4,6\}=\{1,2,3,4,5,6\}, \\
& A=\{1,2,3,4,5,6\} ; B=\{7,8\} \text {; } \\
& \text { 5). } S_{1}^{4}=S_{1}^{3} \cup \mathrm{P}_{r 3} 1 \cup \mathrm{P}_{r 3} 2 \cup \mathrm{P}_{r 3} 3 \cup \mathrm{P}_{r 3} 4 \cup \mathrm{P}_{r 3} 5 \cup \mathrm{P}_{r 3} 6=X \\
& A=X, B=\varnothing \text {. }
\end{aligned}
$$

Tуг $\operatorname{Pr}_{3} 1$ - третя проекція кортежу, що описує верпину $1(\mathrm{i}=1) \mathrm{i}$ далі за аналюгією.

Оскільки при побудові четвертого околу вершини 1 друга множина виявилася пустою, п'ята початкова умова не може служити відправною точкою для пошуку екстремуму.

Таким чином, для знаходження . локального екстремуму ми масмо чотири початкових умови $(1,2,3,4)$. Розв'язусмо задачу для кожної 3 них, використавши алгоритм, наведений в роботі [2].

Для першої умови масмо:

кортеж першої вершини $-<1,2,\{2,3\}>-$ всі вершини третьої проекції $(2,3)$ чужі, але згідно із умовою фізичної задачі вершина 1 належить множині $A$, тому іï переносити не можна;

кортеж другої вершини - $<2,3,\{1,3,5\}>-$ "своїх" вершин $(3,5)$ більше, ніж "чужих" (1);

кортежк трегьої вершини - <3, 3, \{1,2,4\}> - "своїх" вёршин $(2,4)$ більще, ніж "чужих" (1).

Ясно, що для всіх інших вершин всі суміжні вершини будуть "своїми".

Відповідно до алгоритму критерієм є кількість розірваних зв'язків.

Тобто число розсічених зв'язків $\mathrm{R}_{1}=\mathbf{2}$.

Локальним переносом поліпшити результат не вдається.

Для другої умови:

$<1,2,\{2,3\}>-$ всі вершини "своі";

$<2,3,\{1,3,5\}>-$ "своїх" вершин $(1,3)$ більше, ніж "чужих" (5);

$\langle 3,3,\{1,2,4\}>$ - "своїх" вершин $(1,2)$ більше, ніж ,чужих" (4);

$<4,2,\{3,5\}>-$ кількість "своїх" вершин (5) дорівнюе кількості "чужих" (3);

$<5,3,\{2,4,6\}>-$ "своїх" вершин $(4,6)$ більше, ніж "чужих" $(2)$.

Тобто число розсічених зв'язків $\mathrm{R}_{2}=2$.

Для третьої умови:

$<4,2,\{3,5\}>-$ всі вершини "свої";

$<5,3,\{2,4,6\}>-$ "своїх" вершин $(2,4)$ більше, ніж "чужих" $(6)$;

$<6,3,\{5,7,8\}>-$ "своїх" вершин $(7,8)$ більше, ніж "чужих" $(5)$.

Тоб̆то число розсічених зв'язків $\mathrm{R}_{3}=1$.

Для четвертої умови:

$\langle 6,3,\{5,7,8\}>-$ "своїх" вершин (5) менше, ніж "чужих" $(7,8)$;

$<7,2,\{6,8\}>-$ кількість "своїх" верпин (8) дорівнюе кількості "чужих" (6);

$<8,2,\{6,7\}>-$ кількість "своїх" вершин (7) дорівнюе кількості "чужих" (6).

Тобто число розсічених зв'язків $\mathrm{R}_{4}=2$. 
Порівнюючи значення критеріїв, отриманих при знаходженні локального екстремуму з різними вихідними умовами, знаходимо найкраще $\left(\mathrm{R}_{3}=1\right)$ й приймаємо його як глобальний екстремум (рис. 2).

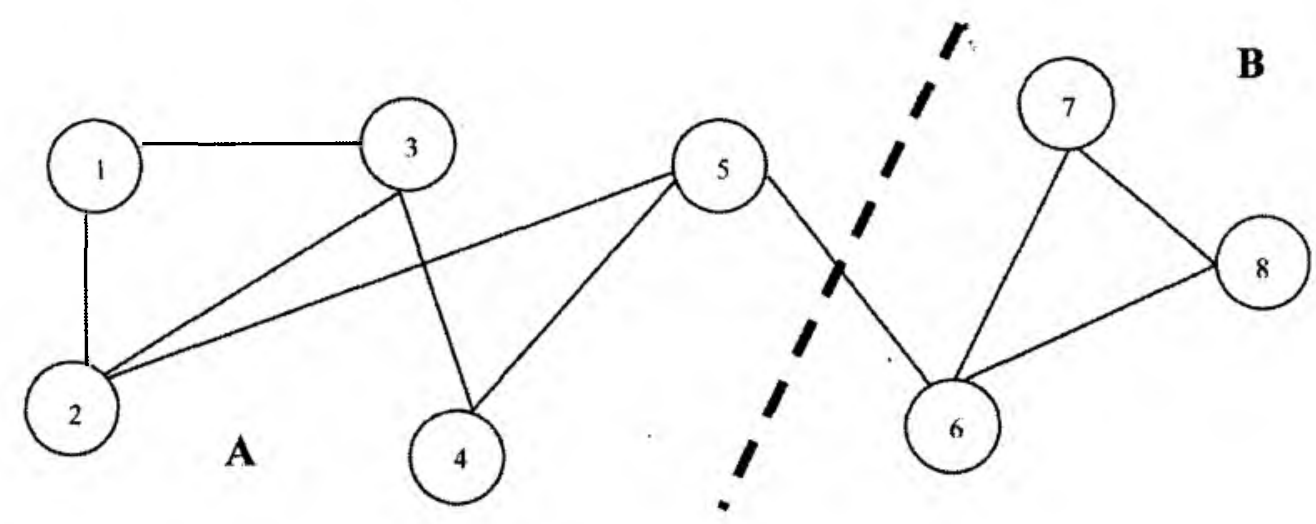

Рис. 2. Геометрична інтерпретація розв'язку після знаходження глобального екстремуму

Джерело: авторська розробка

Висновок. Запропонований в роботі опис графу дає можливість отримання природних вихідних умов для організації пошуку глобальноғо екстремуму в задачі розподілу взаємопов'язаних ресурсів.

Подальші дослідження авторів у цій галузі будуть спрямовані на включення в розгляд обмежень на кількість множин та урахування їх приймальних можливостей.

\section{Список використаних джерел}

1. Абчук В. А. и др. Справочник по исследованию операций / Под общей редакцией Ф. А. Матвейчука. М.: Воениздат, 1979.368 с.

2. Сбітнев А. І., Козлов В. В. Алгоритми розподілу взаємопов'язаних інформаційних ресурсів // Науковий вісник Національної академії статистики, обліку та аудиту. 2013. Вип. 4(39). С. 104-108.

3. Сбитнев А. И. Структурная организация и проектирование математического обеспечения АСУ ТП: дис. ... д-ра техн. наук: 05.13.11 / Сбитнев Анатолий Иванович. K., $1989.447 \mathrm{c}$.

4. Козлов В. В., Сбітнєв А. І. Формулювання задачі розподілу взаємопов'язаних ресурсів, як задачі математичного програмування // Науковий вісник Національної академії статистики, обліку та аудиту. 2014. Вип. 3(42). С. 86-90.

5. Сбітнєв А. І., Саленко К. А. Використання аналітичного подання графів при аналізі структур робіт, виконуваних при плануванні бойових дій // Труди академії. 2001. № 32. C. 349-352.

6. Сбітнєв А. І., Козлов В. В. Систематизація та загальний аналіз сучасного стану прикладних задач розподілу зв'язаних ресурсів і методів їх розв'язку // Прикладна статистика: проблеми теорії та практики. 2011. Вип. 9. С. 96-103.

7. Козлов В. В. Щодо використання зв'язаних ресурсів при проектуванні організаційних структур // Бухгалтерський облік, аналіз та аудит: проблеми теорії, методології, організації. 2011. Вип. 1(6). С. 116-123.

8. Абчук В.А. и др. Справочник по исследованию операцій / Под общей редакцией Ф. А. Матвейчука. М.: Воениздат, 1979.368 с. 
доктор технических наук, профессор, действительный член Международной академии компьютерных наук и систем, заслуженный деятель науки и техники Украины

B. B. КОЗЛOB, ' кандидат технических наук, доцент кафедры информаиионных технологий, Национатьная академия статистики, учета и аудита

\title{
Поиск глобального экстремума в задаче распределения связанных ресурсов
} в работе предложено растирение алгоритма сформулированной обобиеенной
математической задачи распределения взаимосвязанных ресурсов для поиска гло-
бального экстремума.
Ключевые слова: алгорити, связанные ресурсы, распределение ресурсов, глобаль-
ный экстремум.

\author{
A. I. SBITNEV, \\ Dsc (Engineering), Professor, \\ Full Member of the International Academy \\ of Computer Sciences and Systems, \\ Honored Worker of Science and Technology of Ukraine, \\ V. V. KOZLOV, \\ $P h D$ (Engineering), \\ Associate Professor of Information Technologies Department, \\ National Academy of Statistics, Accounting and Audit
}

\section{Search for a Global Extremum in the Problem of Allocation of Connected Resources}

Methods for solving the problems of resource allocation occupy an important place among the mathematical methods for solving special problems in making decisions for the preparation and conduct of the operation. With the emergence of a new kind of resource - information, the characteristic feature of which is internal interrconnection, distribution problems acquire a new meaning. The purpose of the study is to offer an extension of the algorithm for searching a local extremum to achieve a global extremum in solving the distribution problems of connected resources.

To achieve global extremum, we use the well-known approach: 1. Generate some initial distribution; 2. We improve it by searching for the local extremum using a special method. 3. After the n-fold execution of the first two steps, the obtained values are compared and the best one is selected and accepted as the value of the global extremum. The essence of the approach proposed in the work is to use as the initial breakdown of "natural» entities on a graph model, which is used in the physical interpretations of the solvable problems of the distribution of connected resources.

The description of the graph proposed in the work gives the possibility to obtain the natural initial conditions for organizing the search for a global extremum in the problem of the distribution of connected resources.

Keywords: algorithm, connected resources, distribution of resources, global extremum.

Посилання на статтю:

Сбітнєв А. І., Козлов В. В. Пошук глобального екстремуму в задачі розподілу пов'язаних ресурсів // Науковий вісник Національної академії статистики, обліку та аудиту: зб. наук. пр.. 2017. №4. С. 87-92.

SCIENTIFIC BULLETIN OF THE NATIONAL ACADEMY
OF STATISTICS, ACCOUNTING AND AUDIT, 2017, № 4

